arch in the morning, and the pale light seen shooting across it, were connected with the same phenomenon."

I have just been informed by a friend whose veracity I would be the last to question, that he saw a very faint arch in the eastern sky on the afternoon of the Ioth inst. (about 4.30 P.M.). There were no clouds near it, while the background was a beautiful azure. The colour of the arch was of a much fainter blue, or, as he calls it, " a whitish blue," and was almost a perfect semicircle. I have not the least doubt that it was a "daylight" aurora; it must be remembered that on the previous night there was a most magnificent aurora borealis.

In conclusion, after carefully examining the facts contained in the various communications to your journal, as well as those which I have collected, I cannot see any reason for doubting the possibility of the aurora borealis being seen by daylight. It will be interesting to know what those daylight phenomena are, if not auroras.

Red Lion Street

\section{The Irish Fern in Cornwall}

YouR correspondent having, much to my regret, so exactly informed the "ruthless collectors" where they are to look for this fern, I fear that after the ensuing autumnal ravages not a single frond will be left to speak for itself. Permit me, therefore, to state that the fern unquestionably grows, or did grow, at the place indicated, and was, I believe, first recognised in I 866 by Mr. Robert Were Fox, F.R.S., who has a plant he thus obtained still growing in his fernery at Penjerrick near this town.

Falmouth, April 29

\section{The Prevalence of West Winds}

IN a letter with this heading in NATURE for February 16th, Mr. Murphy has very roundly objected to certain views which I have put forward regarding the predominance of westerly winds. In the paper read before the British Association, to the abstract of which he refers, and which was itself little more than a résumé of the propositions maintained at greater length in my "Physical Geography," reviewed by "A. B." in NATURE for March I6th, my object was not so much to show that westerly winds predominated in volume over easterly winds, as to show that all prevailing winds, not westerly, may be properly con. sidered as deflected or secondary currents of air, and that more especially the trade winds may be so considered. I have sup. ported this view by a detailed examination of the geographical circumstances, habitudes, and characteristics of the principal winds ; but to have included every local exception-as "A. B." seems to consider I ought to have done-would have required more time than even the most industrious can spare, all amount of special topographical knowledge which is practically unattainable, and would have had no important bearing on the main question. I may go even further. I may say that, from a general point of view, isolated local registers have no value at all, unless the method of observing and the position of the vane are distinctly made known. It would be perfectly easy to name a dozen localities in Wales, in the Lake District, or in Scotland, where a vane would show a prevailing wind widely different from the W.S.W., which, however, we have no difficulty in accept. ing as the prevailing wind of the country; even at Liverpool the prevailing wind has been observed to be W.N.W., and at Valentia there is a marked difference between the wind in the northern and southern entrance. In Mr. Buchan's paper in the Transactions of the Royal Society of Edinburgh, December, 1869, I find that at Irkutsk the wind is almost always due north, or due south, would "A. B." imply that the Irkutsk observations afford any information as to the prevailing wind of Siberia?

In another paragraph, "A. B." considers that the preponderance of westerly winds cannot be very great. So far as the area over which westerly winds blow is concerned, I would partly agree with him; taking into account the constant interruptions to the west winds in the temperate zones, and on the other hand their frequent intrusion into latitudes considerably below $30^{\circ}$, more especially in the Pacific, and their prevalence during several months of the year over a large portion of the Indian Ocean, Iam inclined to reckon the ratio of the area of westerly winds to the area of easterly winds as approximately $13:$ 10. But such an estimate

* Jameson's Journal, unoted in the "Arcana of Science and Art" for $x_{2} 8$. does not in any way include the velocity of the wind ; and since the velocity of the west winds of temperate latitudes is, in the mean, about double that of the easterly winds of tropical, it would follow that the respective volumes of the winds bear to each other a much larger ratio, which, allowing freely for every reasonable reduction, cannot be less than $2: \mathrm{I}$. And this estimate still relates only to the lower strata of the atmosphere, through a height probably not exceeding 12,000 feet. Our knowledge of the winds above that height is very limited ; but since, wherever observation extends, it points out to us a strong, frequently even a violent west wind, it seems to me that we have a fairly presumptive proof that the prevailing direction of the upper current is from the west. I base this belief entirely on the evidence which we have, defective as it is and as it almost necessarily must be ; to explain the fact by a reference to a difference of barometric pressures, concerning which we have positively no evidence at all, is a task which I most willingly leave to my reviewer. But if, as I have maintained, we may fairly assume that the upper current has an almost invariable direction from the west, and that too with a comparatively high velocity, the ratio of the volumes of westerly and easterly winds is enormously increased, and if the upper part of the air, being quite half of the whole, is moving from the west with a mean velocity of 40 miles an hour, then, as we have already taken 20 miles, or the velocity of the trade winds, as the standard or unit of reference, we have the ratio of westerly to easterly winds as about $6: \mathbf{I}$.

The question which Mr. Murphy has suggested no doubt here arises : Must not this preponderance of westerly winds affect the rotation of the earth? I have throughout maintained the exis. tence of this preponderance solely by geographical proof, and conceiving that the evidence is conclusive, whilst no meteorological theory points to any explanation of it, I am compelled to attribute it to the action of some force external to the earth possibly, as I have endeavoured to show, to the attraction of the sun, moon, and other heavenly bodies ; possibly also to some other force, magnetic or meteoric, of whose action we have as yet no knowledge or understanding : but supposing, as I do, that the force which produces this motion is external to the earth, it is impossible to avoid the conclusion that it does tend to increase the earth's velocity of rotation. On the other hand, there are forces, ad mitted by all naturalists, in constant action, which tend to decrease the velocity of rotation; and a certain amount of wonder that the decrease so caused is so small as observation proves it to be is implied, rather than expressed, in our most valuable works on Natural Philosophy. If it is impossible in the present state of our knowledge to show exactly what such decrease is and ought to be, it is certainly impossible to say that it is not to some extent counterbalanced by a contrary tendency towards an increase, such as I have shown probably exists. At any rate, I know of nothing connected with the rotation of the earth which in any way controverts or affirms the proposition which I have put forward, based on geographical evidence only.

I had written this before seeing Mr. Murphy's second letter on the subject in NATURE for March 30 , but as he has in it merely repeated his former arguments, it is unnecessary to notice it more particularly.

Royal Naval College, Portsmouth

J. K. LAUGHTON

$=$

\section{SUBMARINE TELEGRAPHS}

$T \mathrm{~T}$ may possibly be within the memory of some persons that, about the year 1840, Sir C. Wheatstone first conceived the idea of transmitting messages under the sea, and practically carried out at that time the first submarine telegraph cable. Selecting Swansea Bay, South Wales, as the chosen spot for his experiment, the great inventor sat in an open boat, about three miles from the Mumbles Lighthouse, with the lighthouse keeper as his assistant. A conducting wire, insulated with hemp and a resinous compound, served as the electric communication between his open boat and the shore. It is from the successful results of this first crude experiment, and Wheatstone's investigations into the laws that regulate the transmission of electric currents through metallic conductors, published shortly afterwards in the Philosophical Transactions of the Royal Society of London, that our present system of the testing of submarine cables is based, 
and the vast system of inter-oceanic communication that connects the civilised world together, has been framed.

At the date of Wheatstone's first experiment, guttapercha was undiscovered, and its insulating power unknown. By the employment of this gum, the electrical condition of the submarine cable, up to a certain standard, has been under ordinary circumstances rendered secure. Such being the case, and for the purpose of comparison hereafter, it is well to examine a little into the properties of this gum and that of india-rubber, another vegetable substance possessing insulating properties of the most remarkable kind, as applied to the construction of submarine cables. Gutta-percha, as is well known, is a vegetable gum, which becomes plastic and soft at a comparatively low temperature, about $100^{\circ} \mathrm{F}$. Subjecting the gum to repeated cleansing processes to free it from impurities and extraneous vegetable matter, it is rendered tolerably dense and homogeneous, and in this state it is applied in successive layers or coats round the copper conducting wire as the insulating material, forming the "core" of the submarine cable, which is then termed "insulated," that is, capable to a certain extent of preventing the lateral escape of any electric current or charge which may be passed into the wire. A short investigation is now necessary to be made of some of the circumstances which take place when a wire thus insulated is submerged and subjected to the charge of an electric current. If the wire were absolutely insulated, that is, if gutta-percha were a perfect insulator offering an indefinite resistance to the passage of the current through its substance, any given quantity of electricity passed into the wire would remain there for a given time without loss, in the same way as when water is poured into a vessel, the level remains intact so long as there is no leakage. The amount of this leakage through the gutta-percha, or, in other words, its "conductive resistance," determines the insulating power of the cable. But this is not all that has to be considered; other circumstances affecting the value of the insulation come into play. The following analogous example will explain. When a leech is allowed to crawl through a glass tube, the head and body pass out first, while the tail-long and attenuated-is slowly withdrawn. So with the passing of an electric current through an insulated conductor, a portion of the current lags sluggishly behind, absorbed, as it were, into the substance of the insulating medium, and taking time to discharge itself in proportion to the amount of the sucking up, or "inductive capacity" of the insulator, for, in this respect, both guttapercha and india-rubber may be regarded as a sponge, the current penetrating into the pores of the substance.

Without entering further into detail regarding the laws regulating the transmission of the current, it is sufficient to remember that the speed or power of transmitting a given number of messages in a given time over any cable depends materially upon the proportionate values of the "conductive resistance" and "inductive capacity" of the insulation. Thus there is at once established a measure by which the value of all known insulating materials may be determined and compared together, that is to say, if two cables of equal length and similar construction are taken-the one insulated with gutta-percha, and the other with india-rubber (Hooper's india-rubber)-the relative value and working speed of each can be accurately determined and compared. The successful employment of india-rubber as an insulating medium for submarine cables is of more recent date, and the estimation in which it is now held for that purpose is entirely due to the beautiful process employed in its manipulation by Mr. W. Hooper, of Mitcham. It is well known that india-rubber possesses a much higher insulating power than gutta-percha; as a gum it is also denser, more homogeneous, and infinitely more pliable and elastic than gutta-percha, while it is not affected in any considerable degree by variation of temperature-all qualities of the greatest importance as connected with submarine cable insulation.

Before entering upon a comparative statement of the insulation and speed of gutta-percha and Hooper's insulation, a short notice of the mode by which this insulating material is manipulated will be interesting, and will serve to give value to the practical data hereafter stated. The copper conductor, after being tinned, is coated with an insulation of pure india-rubber applied in the shape of a ribbon, lapped spirally round it. Next, two strips (one laid above and the other below) of indiarubber, chemically prepared to resist the action of sulphur, and called the "separator," are applied so as to completely surround the first rubber covering, as it were with a tube; a pair of grooved die-wheels giving the contour, and at the same time regulating accurately the guage of the core. Exterior strips are then similarly applied of a compound of rubber and a small percentage of sulphur. The whole is then lapped round with water-proof felt tape, and exposed for some hours in an oven to a heat of about $383^{\circ} \mathrm{F}$. By this process the tr.ree successive coatings are welded into one solid, dense, homogeneous mass, having its distinctive features preserved as regards the individual character of the several layers. Thus the heat, in driving off the sulphur from the outside coating, has converted that envelope into an indestructible vulcanised rubber jacket. The second layer, or "separator," has intercepted the passing of the sulphur by reason of its chemical properties, while at the same time it has allowed an infinitesimal trace of the sulphur to combine with the internal coating of pure rubber round the conducting wire, sufficient to change its character into an indestructible and nonliquifying material, without its becoming in any way vulcanised. It is by this beautiful chemical affinity between the several layers, each periorming its special part towards the production of one individual whole, that the "Hooper insulation" has succeeded in establishing the durability of the preparation, the comparative value of which, as compared with that of gutta-percha, will now be given.

First as regards temperature-it has been already stated that gutta-percha became plastic at about $100^{\circ} \mathrm{F}$. At this temperature it loses also almost entirely its insulating properties; that is to say, if at a temperature of $32^{\circ} \mathrm{F}$. the insulation of gutta-percha is taken as representing 100 , at $75^{\circ}$ it is reduced to 5.51 , or little more than a twentieth part, while at the increased temperature of $100^{\circ}$, its insulating power has further decreased to $\mathrm{x} 43$, or about one seventieth part. Guttapercha as an insulator is therefore unsuited for hot climates, or any exposed position where the temperature rises above $70^{\circ}$. Taking now Hooper's india-rubber insulation at $32^{\circ} \mathrm{F}$. to be the same, 100 , at $75^{\circ}$ we find its insulation to be 2450 , or about one-fourth part, while at $100^{\circ}$ it is I0.60, or about one-tenth part. Thus at the ordinary temperature of $75^{\circ}$, Hooper's core establishes its stperior insulating properties under temperature in the proportion of four to one. The "inductive capacity" of Hooper's core, from its superior density, is only about two-thirds that of gutta-percha, while its insulation or resistance of the dielectric is fully twenty times greater than that of gutta-percha core, as exemplified in the tests given of some of the best known cables now at work.

The following is a list of some of the more important cables insulated with Hooper's core laid up to the present time :-

I. Cable crossing rivers in Inclia, laid in 1865 , length 46 nauts.

2. Ceylon Cable, India, laid in 1866 . . , 35 ,

3. India Cable

4. Persian Gulf Cable

5. Danish-English Cable

6. Scotch-Norwegian Cable

7. Danish-Norwegian Cable

8. Orkney and Shetland Islands Cable. : " " 73 " 
9. Pentlands Cable
Io. Scilly Islands $\mathrm{Cabl}$

II. Swedish-Rusșian Cable

12. Mnen Bornholm Cable

13. Hong-Kong-Shanghae Cable

14. Shanghae-Possiette Cable

These two latter cables have recently been completed, and the Shanghae-Possiette cable is now in course of submergence; the Hong-Kong-Shanghae cable was successfully laid last month. These lines give a total distance of over 3,978 nautical miles of submarine cable with Hooper's indiarubber insulation. The following observations as regards the electrical conditions of these cables as compared with well-known gutta-percha insulated cables is remarkable. The electrical tests of well-known cables with both the gutta-percha and the Hooper core are taken at the temperature of $75^{\circ} \mathrm{Fahr}$, and in terms of British Association (B.A.) units, the standard measure now most generally adopted in England for comparison :

Gutta-percha.

England and Hanover Cable, laid I866 . 239 million B. A. units Persian Gulf Cable . ", 1864. 190 Atlantic Cable • . ", 1865 . 349 Atlantic Cable : . , I866 . 342, l'acentia Bay Cable 1866.455 Cuba and Florida Cable: " " I867. 464

Hooper Core.

\begin{tabular}{|c|c|c|c|}
\hline Ceylon Cable (Hoc & Core) , & 1865 & \\
\hline India Cable & " & $1865 \cdot 8004$ & $"$ \\
\hline Inolia Cable & & $1866 \cdot 8526$ & $"$ \\
\hline J)anish-English Cable & ", & 8123 & $"$ \\
\hline Szotch-Norwegian Cable & ", & 7923 & $"$ \\
\hline Scilly Islands Cable & , & 1870 & $"$ \\
\hline
\end{tabular}

With such results, it is not to be wondered at that the relative speed of two cables of similar length and construction, the one employing a gutta-percha core and the other a Hooper core, should be found greatly in favour of the latter, in the proportion of 130 to 100 ; that is to say, in any given time the Hooper core, from its superior insuliting properties, will transmit thirty per cent. more words than a gutta-percha core, a most important circumstance when it is considered that the earnings or dividend upon each cable is dependent upon the work it can perform in a given period. As regards the apparatus employed for transmitting the currents through submarine conductors, the "Wheatstone" automatic recording system is the most successful. By this apparatus an average speed of over thirty words a minute is regularly maintained upon the Danish-English cable, a distance of 363 nautical Iniles, exclusive of a further land circuit of over I40 miles, making a total distance of about 500 miles. This speed must be compared with that of seventeen words per minute, the highest result recorded over the same circuit by the most improved Morse system. From the results of the "Wheatstone" apparatus working over this circuit since September I868, it appears that to obtain maximum speed, the currents through a submarine cable require to be transmitted of equal duration, at equal intervals, in alternate directions, and the line discharged to earth between each successive reversal or current to neutralise the charge, all of which conditions are fulfilled in the "Wheatstone" Automatic Jacquard arrangement, which can only be compared to a loom weaving the currents into the line, the sequence of the currents representing the pattern on the cloth. This apparatus is now organised as the transmitting and recording register upon the vast system of submarine circuits belonging to the Great Northern Telegraph Company, and the extensions from Possiette Bay (RussianChinese frontier) to Nagasaki, Shanghae, and Hong-Kong. The subject of high speed transmission through insulated conductors, both by land and sea, is one which demands special attention, now that the telegraph is daily encroaching upon the postal service, a service in which both speed and accuracy are more than ever demanded by the public. NATH. J. HOLMES

\section{PFLÜGER'S NERVE:ENDINGS IN GLANDS}

T $N$ his "Archiv für die Gesammte Physiologie" (Bonn, I87 I), E. Pflüger gives a short and summary answer to those many observers who have thrown doubt on the accuracy of his remarkable discoveries as to the continuity of nerves with the secreting cells of the salivary glands and liver. Pflüger's opponents in this matter have been Mayer, Hering, Krause, Henle, and Schweigger-Seidel. The objections which have been made are divided by him into three heads. Ist. It was said that the nerves he had seen were capillary vessels. 2nd. That they were threads of mucus. 3 rd. They were disintegrated fat. These objections are successively shown to be groundless, and Pfluger stoutly maintains his original position. What is far more important in this short paper than these answers to objections is that the professor at length publishes an account of some of his methods as to which he has so long left every one in the dark. They are certain to be interesting to some of our readers. Salivary glani's. A fresh submaxillary gland from the ox must be taken, and very fine sections made; these must be at once teased out in perosmic acid sp. gr. I003, and covered with a thin glass in a shallow cell. A great many preparations should be made, and the best picked out. They will be sufficiently stained in 24 hours, As the water dries up it may be replaced by glycerine. Liver. A great number of very fine sections must be made from the fresh liver of a dog or pig. These sections must be placed Io or 12 together in watch-glasses filled with Beale's carmine solution, and thus kept in a moist chamber I4 days. The sections must then be taken out, washed one by one in a drop of perosmic acid, sp. gr. IOO3, transported to a fresh drop of the same on a slide, and carefully teased out, covered, and examined.

\section{NOTES}

ST. BARTHOLOMEW's Hospital has, we learn from the British Medical Fournal, sustained a great loss in the resignation by Mr. Paget of his active duties as Surgeon to the Hospital. Mr. Paget will, of course, receive the appointment of Consulting Surgeon to the Institution which he has served long and faithfully, and on which he has conferred lustre.

THE following excursions have been arrarged by the Geologists' Association to take place in May :- To Oxford on Friday, 12th May. On arriving at Oxford the New University Museum will be visited. Subsequently the party, accompanied by the President, Prof. Phillips, and Prof. Morris, will walk to Shotover Hill, where the Middle and Upper Oolites are well exposed. To Grays, Essex, on Saturday, 2oth May. Exposures of the Mammaliferous beds of the Thames Valley, and afterwards sections of the Upper Chalk will be visited, under the guidance of Prof. Morris. A four days' excursion to Yeovil, Weymouth, and Portland is proposed for Whitsuntide. Particulars of arrangements will be duly announced.

THE Edinburgh Naturalists' Field Club, which has since its formation carried on active operation only from April to July inclusive, held its adjoumed annual meeting and conversazione on Saturday, the 22nd April, when Mr. Robert Scot-Skirving, the president, delivered an introductory address, enlarging mainly on entomology as a fit summer field study. The business meeting was held in November last, when, in addition to the 